症 例

健常者に発症し短時間で急激に増悪した緑膿菌市中肺炎に対し, 出血制御目的に上葉切除術を施行した 1 例

松尾＼cjkstart翼, 藤嶋 悟志, 細野由希子, 三井 匡史

要

旨

症例は 53 歳, 男性. 胸背部痛と呼吸苦を主訴に救急搬送された. 救急外来での診察中に右上葉気管支からの出血が持続し, 血気胸合併により急激に呼吸状態が悪化したため, 喀血および血胸の制御目的に緊急で右肺上葉切除を施行した，術後，急 速に多臟器不全が進行し, 術後 5 時間で死亡した。喀疾培養, 血液培養では緑膿菌が検出され，切除標本の病理検查でも緑 膿菌による出血性肺炎の診断であった，健常成人での緑膿菌市中肺炎は極めて稀であり，急速に呼吸不全が進行して致死率 が高いとされているが, これまで出血が問題となった報告は認められない. 今回, 喀血と血気胸に対して外科的止血を施行 するも, 敗血症による多臟器不全のため救命困難であった 1 例を経験したため, 報告する.

索引用語：緑膿菌，市中肺炎，出血性肺炎

Pseudomonas aeruginosa, community-acquired pneumonia, hemorrhagic pneumonia

はじめに

緑膿菌は通常, 院内肺炎など日和見感染症の代表菌と して広く認識されているが, 非常に稀ながら健常者に発 症した緑膿菌市中肺炎の報告例がある。これらの報告で はいずれも急激で重篤な経過をたどるとされる.今回 我々は，健常者に発症し，大量喀血と血気胸をきたした 緑膿菌市中肺炎の 1 例を経験したため報告する.

\section{症例}

症 例 : 53 歳, 男性.

主 訴：胸背部痛, 呼吸苦.

現病歴：3 日前から自覚していた両側の胸背部痛や䀻燕 下時咽頭痛が徐々に増悪して呼吸苦も出現したため救急 要請し, 当院へ搬送された。

既往歴：特記事項なし.

八戸市立市民病院呼吸器外科

原稿受付 2018年 7 月 8 日

原稿採択 2018年 8 月27日

本論文の要旨は第 35 回日本呼吸器外科学会総会・学術集会 にて発表した。
アレルギー歴：なし.

喫煙歴 : 30 本/日 $\times 33$ 年.

来院時現症：意識清明, 血圧 $69 / 49 \mathrm{mmHg}$, 脈拍 118/ 分, 酸素飽和度 $90 \%$ (室内気), 呼吸数 30 回/分, 体温 $37.4^{\circ} \mathrm{C}$, 右胸部で水泡音を聴取した. 気道内より大量の鮮 血が吸引された。

血液検査所見：WBC $3400 / \mu \mathrm{l}, \mathrm{Hb} 13.4 \mathrm{~g} / \mathrm{dl}, \mathrm{Plt} 12.3$ 万/ $\mu \mathrm{l}, \mathrm{PT} 64 \%$, PT-INR 1.36, APTT 45.6 秒, CRP 19.98 $\mathrm{mg} / \mathrm{dl}$. 血清クレアチニンが $2.28 \mathrm{mg} / \mathrm{dl}$ と高值であり， $\mathrm{PaO} 2 / \mathrm{FiO} 2 \leqq 200$, 低血圧と併せて Sequential Organ Failure Assessment Score（SOFA score）は 6 点と敗血 症の状態であった．免疫不全を示すような肝機能障害や HIV 感染は認めなかった

喀痰塗抹検查：白血球とグラム陰性桿菌を多数認め た.

胸部 $\mathbf{X}$ 線写真：右上肺野に広範な浸潤影を認めた (Fig. 1A).

胸部 CT : 右肺上葉全体に気管支透亮像を伴う浸潤影 と両側上肺野優位の気腫性変化を認めた（Fig. 1B）.

臨床経過：来院時は意識清明で会話可能であったが,

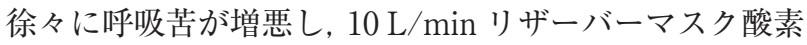



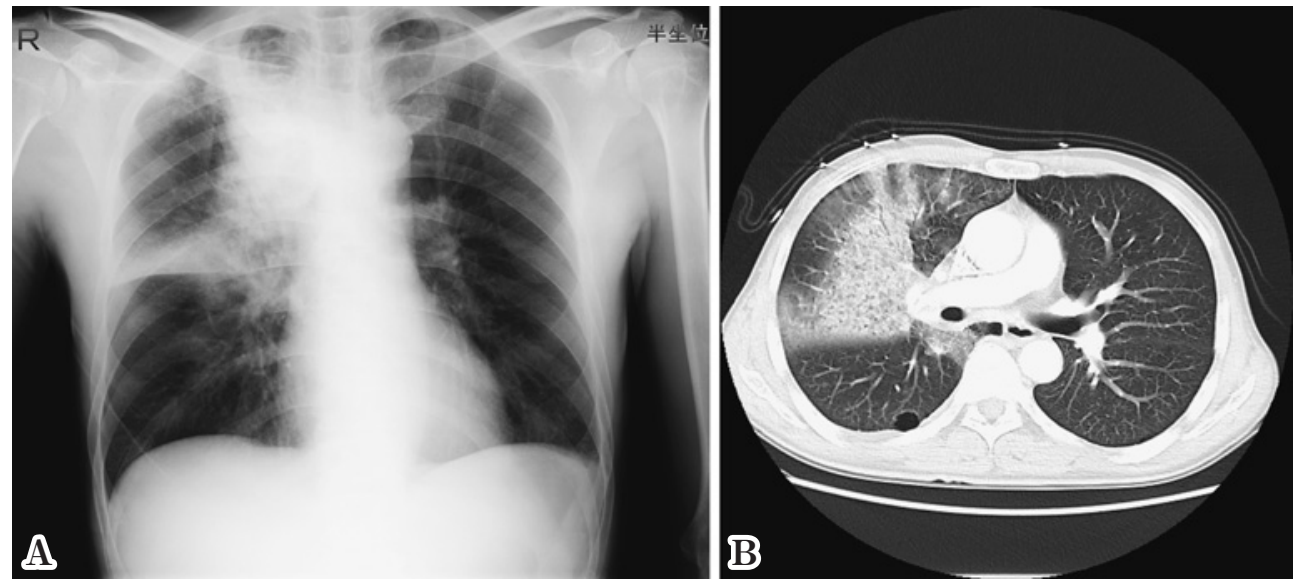

Fig. 1

A: A chest radiograph on admission showed a consolidation shadow in the upper lung field.

B: Chest CT revealed lobar pneumonia of the right upper lobe.

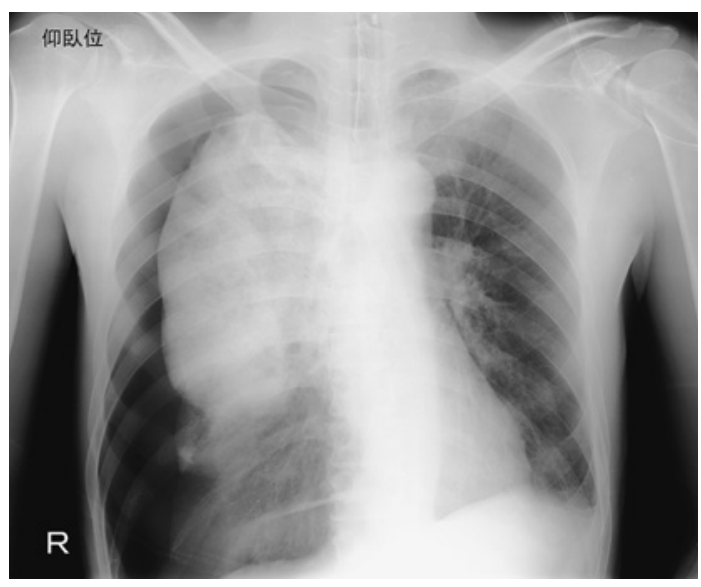

Fig. 2 Chest radiograph showing right pneumothorax.

投与下でも酸素化を保てず，気管内挿管を行った，その 後, 挿管チューブ内から鮮血が噴出するため, 気管支鏡 で確認すると右上葉気管支からの持続的な出血が認めら れた。同時に胸部 X 線写真で右気胸を認めたため, 胸腔 ドレーンを留置した（Fig. 2). 脱気されると共に約 600 $\mathrm{ml}$ の血性胸水が流出した. 胸腔ドレナージ後は一時的に 酸素化の改善を認めたが, 再び呼吸不全が進行, 収縮期 血圧も $40 \mathrm{mmHg}$ 台に低下して頸動脈触知不可となり, 直後から心電図波形上も心停止となったため胸骨圧迫を 開始し, 心拍再開後に経皮的心肺補助装置 (percutaneous cardiopulmonary support ; PCPS) を導入した. その 後, 持続する気道内出血および血胸のコントロール目的 に緊急手術を行う方針とした.
手術所見：第 5 肋間後側方切開で開胸し，手術を開始 した，胸腔内には中等量の血性胸水の貯留を認め, 上葉 は著明に榃血していた，胸腔内への出血部位を検索する と, S6 の肺囊胞と縦隔側胸膜の間の索状の癒着が切断さ れており, 同部位から動脈性の出血を認めた。この出血 点を凝固止血したが，胸壁のいたるところから oozing が認められた．また，気管支鏡で観察すると上葉気管支 からの気道内出血も持続していたため, 上葉切除を施行 した．胸壁全体からの oozing を可及的に止血し，2 本の ドレーンを留置して閉創した。手術時間は 2 時間 56 分, 術前からの胸腔内貯留分を含めて出血量は $1120 \mathrm{ml}$ あった。

術後経過：大動脈内バルーンパンピングや持続的血液 滤過透析を併用して全身管理を行ったが, 循環動態が低 下してPCPS のフローを維持できなくなり, 心停止, 死 亡確認した. 来院から死亡確認までは 14 時間半の経過で あった。

後日, 血液培養と喀痰培養から緑膿菌が検出された。 切除標本の病理検査では, びまん性の出血と共に肺胞内 への好中球浸潤を認め, 肺組織の広範な凝固壊死と内部 に多数のグラム陰性桿菌の菌塊形成を認め, 緑膿菌によ る出血性肺炎に矛盾しないとの診断であった（Fig. 3).

\section{考察}

緑膿菌は院内肺炎や人工呼吸器関連肺炎の起因菌とし て最も頻度が高いグラム陰性桿菌である。一方, 市中肺 炎のうち緑膿菌が原因であるものは $0.1 \sim 2.0 \%{ }^{1)}$ とされ, 

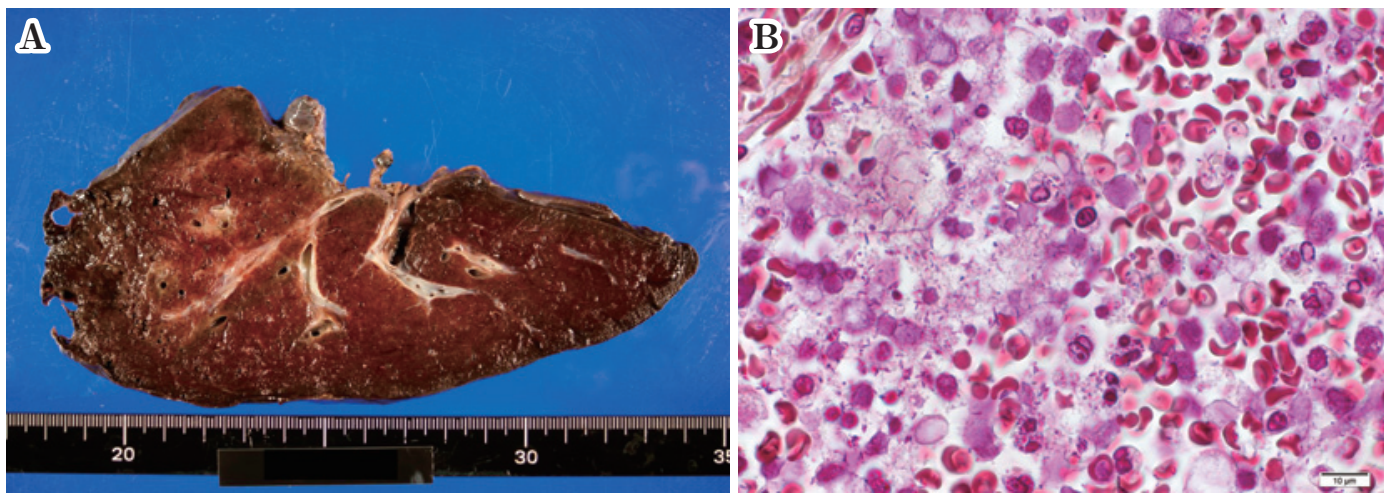

Fig. 3

(A) The resected specimen of the right upper lobe showed low aeration and a red wine color because of bleeding.

(B) Gram stain of the resected specimen showed gram-negative rods engulfed by a leukocyte.

好中球減少症，慢性呼吸器疾患などの基礎疾患をもつこ とや直前までの抗生剂投与歴，気管挿管の既往，経管栄 養などが危険因子とされる，本症例では呼吸器疾患を含 む基礎疾患はなく，免疫不全状態を示す所見も認めな かった，基礎疾患をもたない健常人に緑膿菌市中肺炎が 発症することは非常に稀で，本邦ではこれまでに 6 例が 報告されているのみである ${ }^{2.6)}$. 本症例を含む健常者緑膿 菌市中肺炎の 7 例全例において, 主訴は胸背部痛であっ た.これは肺炎の重症化に伴う胸膜刺激症状と考えられ， 緑膿菌市中肺炎に特異的症状とはいえないが, 有意な所 見と考えられた。

Hatchette らによる健常者緑膿菌市中肺炎の 12 症例 の報告では, 死亡率は $33 \%$ と高率であり, $92 \%$ の症例で 菌血症を呈していた . 入院から死亡までの平均時間は 11 時間であり，短時間で急激に悪化したことが示唆され ている. 本症例に㧈いても来院からの急激な経過や菌血 症など同様の臨床像を示した．また，同報告では 12 例中 8 例で病変が右上葉に局在したとされている，本邦での 過去 6 例の報告でも 5 例が右上葉病変, 1 例が左上葉病 変であり, 有意に右上葉病変の報告が多い。稀な疾患で あり，緑膿菌市中肺炎が右上葉に起きやすいかどうかは 不明であるが，Ferrero らや Kin Key らによる小児にお ける肺炎の画像所見についての多変量解析では, 上葉病 変は菌血症などと関連しており，重症化を示す因子とし て報告されている ${ }^{8,9)}$. 緑膿菌市中肺炎においても上葉病 変であることが重症化のリスク因子となり，そのため報 告例が上葉病変に偏っている可能性がある.

重症化をきたす機序として, 緑膿菌の中には III 型分
泌システムといわれる特殊な分泌装置で細菌菌体から標 的真核細胞の細胞質へ直接病原体毒素を注入し，毒素が 真核細胞の細胞質に転移した後に真核細胞の活性化因子 により活性されて酵素作用を発揮する細胞株がある ${ }^{10.111}$. このような細胞株は急速な肺上皮細胞壞死，全身播種， 敗血症を誘発するとされ，動物モデルにおいては，急性 肺損傷掞よびそれに続発する敗血症を誘発する緑膿菌株 は, III 型分泌システムの分泌蛋白である ExonzymeU を発現している ${ }^{10)}$. 緑膿菌市中肺炎の報告例の中には血 痰がみられた症例はあるが，本症例のように喀血が持続 した報告はみられなかった ${ }^{2 \cdot 6)}$. 本症例で分離された緑膿 菌株について細菌学的特徵の評価は行っていないが，同 様の機序を有する細菌株により，急速な肺上皮細胞壊死 が起こり，敗血症による出血傾向も重なったことで，コ ントロール困難な出血性肺炎が惹起されたと推測する. 喀血に対する治療としては内視鏡的止血術，気管支動脈 塞栓術，外科的止血術などが挙げられる。本症例でもま ず内科的止血術を検討したが，急激に増悪して心停止に 至り，心拍再開後も血圧を維持できず時間的猶予がな かったこと，気道内出血のみならず血気胸も伴っていた ことから, 救命救急科, 放射線科との協議の末に外科的 止血術に踏み切った。結果的に止血は得られたものの, 多臟器不全の進行により救命困難であった，救急外来で 急激な呼吸状態の悪化, 喀血, 気胸, 血圧低下などの対 応に追われ，抗生剤投与のタイミングが遅れたことや基 礎疾患のない健常若年者であったため, 緑膿菌感染の可 能性を考虑していなかったことが反省点であった，胸背 部痛を伴う上葉優位の肺炎の場合には，健常者であって 
も緑膿菌をカバーした抗菌薬を選択したうえで, 急激な 増悪が起きる可能性があることを念頭に置くべきである と考えられた。

\section{結語}

急激に増悪した健常者緑膿菌市中肺炎による喀血, 血 気胸に対して外科的止血術を施行した 1 例を経験した。 胸背部痛で発症し, 上葉に病巣がある健常者市中肺炎の 場合, 緑膿菌を起炎菌として急激に増悪し, 致死的な経 過をたどる可能性があることを念頭に置く必要がある.

\section{利益相反}

本論文について申告する利益相反はない.

\section{文献}

1. File TM. Community-acquired pneumonia. Lancet 2003; 362: 1991-2001.

2. Kunimasa K, Ishida T, Kimura S, Tanaka M, Kouyama Y, Yamashita S, et al. Successful treatment of fulminant community-acquired Pseudomonas aeruginosa necrotizing pneumonia in a previously healthy young man. Intern Med 2012; 51: 2473-8.

3. Okamoto M, Yamaoka J, Chikayama S, Ohishi T, Nakajima T, Nakashima T, et al. Successful Treatment of a Previously Healthy Woman with Pseudomonas aeruginosa Community-acquired Pneumonia with Plasmapheresis. Intern Med 2012; 51: 2809-12.

4. Ishihara S, Takino M, Okada Y, Mimura K. Septic shock due to Pseudomonas aeruginosa in a previously healthy woman. Intensive Care Med 1995; 21: 226-8.

5. 佐々木朗, 柳 重久, 長野健彦, 松元信弘, 落合秀信, 中 里雅光. 健常者に発症し, 敗血症性ショックと急性呼吸促 迫症候群から救命しえた緑膿菌市中肺炎の 1 例. 日呼吸 誌 2015; 4: 110-5.

6. 高倉 晃, 上遠野健, 原田真也, 井川 聡, 片桐真人, 矢 那瀬信雄, 他. 急激な経過を辿った緑膿菌による市中肺炎 の 2 例. 感染症誌 2015; 89: 56-61.

7. Hatchette TF, Gupta R, Marrie TJ. Pseudomonas aeruginosa community-acquired pneumonia in previously healthy adults: case report and review of the literature. Clin Infect Dis 2000; 31: 1349-56.

8. Ferrero F, Nascimento-Carvalho CM, Cardoso MR, Camargos P, March MF, Berezin E, et al. Radiographic findings among children hospitalized with severe community-acquired pneumonia. Pediatr Pulmonol 2010; 45: 1009-13

9. Kin Key N, Araujo-Neto CA, Nascimento-Carvalho CM. Severity of childhood community-acquired pneumonia and chest radiographic findings. Pediatr Pulmonol 2009; 44: $249-52$.

10. 佐和ていじ，緑膿菌性肺炎・敗血症と III 型分泌システ 厶. 日集中医誌 $2001 ; 8: 305-10$.

11. 佐和貞治, 加藤秀哉, 安本寛章, 清水 優, 濱岡早枝子, 木下真央, 他. 緑膿菌の主要肺傷害因子一パタチン様ホス ホリパーゼ A2-III 型分泌毒素 ExoU一，京府医大誌 2015; 124: 475-87. 


\title{
Upper lobectomy to control bleeding caused by rapidly developing Pseudomonas aeruginosa community-acquired pneumonia in an otehrwise healthy man
}

\author{
Tsubasa Matsuo, Satoshi Fujishima, Yukiko Hosono, Masafumi Mitsui
}

Department of Thoracic Surgery, Hachinohe City Hospital, Aomori, Japan

A 53-year-old man was referred to our hospital with chest and back pain and dyspnea. We performed an emergency right upper lobectomy to stop the bleeding by hemoptysis and hemothorax. Multiple organ failure followed and he died 5 hours after surgery. Pseudomonas aeruginosa was detected in sputum and blood cultures. Pathological examination of the resected specimens led to a diagnosis of hemorrhagic pneumonia caused by Pseudomonas aeruginosa pneumonia. Community-acquired pneumonia caused by Pseudomonas aeruginosa is extremely rare. Respiratory failure progresses rapidly and the mortality rate is high, but there has been no report of Pseudomonas aeruginosa pneumonia causing hemorrhagic shock due to hemorrhagic pneumonia. We report the use of surgery to stop the bleeding due to hemoptysis and hemothorax caused by Pseudomonas aeruginosa community-acquired pneumonia.

(C) The Japanese Association for Chest Surgery (JACS) 